\title{
Paediatric and adult critical care medicine: joining forces against Covid-19
}

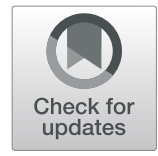

Martin C. J. Kneyber ${ }^{1,2^{*}}$, Bernadette Engels ${ }^{1}$ and Peter H. J. van der Voort ${ }^{2,3}$

The increasing number of COVID-19 intensive care unit (ICU) admissions in our hospital necessitated increasing the number of physical ICU beds and staffing. This could be done by redeploying paediatric critical care physicians and nurses to adult ICUs. However, paediatric ICUs (PICU) are exclusively located in university hospitals in the Netherlands, hence redeployment potentially could reduce capacity for critically ill children [1]. We thus decided to maintain our current PICU capacity and to re-open, for adult COVID-19 care, the part of our PICU that was closed due nursing staff shortage [2].

The main hurdle was how to staff the unit. PICU physicians and nurses advocated to remain in their environment and use the well-established working relationships within the PICU bedside team when caring for the adult COVID-19 patients because the general principles of intensive care medicine would not be different between children and adults [3]. Also, the clinical phenotype of adults with COVID-19 matched perfectly the research focus of our PICU, providing opportunities to study respiratory system mechanics in these adults [4]. To increase availability of PICU nurses, we upgraded their employment contract to 1 full-time equivalence, and all granted leaves of absence were revoked until further notice after consulting Human Resources and approval of the Board of Directors.

The entire nursing team was split into two. One group of nurses originally coming from the adult ICU before becoming a PICU nurse were exclusively allocated to the COVID-19 part of our PICU. These nurses and our own PICU consultants were the primary care providers. An adult intensive care unit consultant reviewed patient plans twice a day to guarantee quality of adult critical care [5].

The 6-bedded Covid-19 unit located in the PICU opened at the end of March and remained open for six weeks. Our ICUs admitted 98 adult COVID-19 patients, 12 of them were treated in the PICU by paediatric nurses and intensivists. All but one of these 12 survived to PICU discharge (Table 1). Preserving the PICU team ensured a rapid transition and boosted morale. This period proved to be a unique

* Correspondence: m.c.j.kneyber@umcg.nl

'Department of Paediatrics, division of Paediatric Critical Care Medicine, Beatrix Children's Hospital, University Medical Center Groningen, University of Groningen, Huispost CA62, P.O. Box 30.001, 9700, RB, Groningen, The Netherlands

${ }^{2}$ Critical Care, Anaesthesiology, Peri-operative \& Emergency Medicine (CAPE), University of Groningen, Groningen, The Netherlands

Full list of author information is available at the end of the article 
Table 1 Characteristics of 12 adult Covid-19 patients managed in the paediatric intensive care unit by the team of paediatric critical care physicians and paediatric critical care nurse

\begin{tabular}{|c|c|c|c|c|c|}
\hline $\begin{array}{l}\text { Age (years); } \\
\text { Gender }\end{array}$ & BMI & $\begin{array}{l}\text { Ventilation time before PICU admission } \\
\text { (days) }\end{array}$ & $\mathrm{PE}$ & $\begin{array}{l}\text { Total ventilation time } \\
\text { (days) }\end{array}$ & PICU discharge \\
\hline $64 ; \mathrm{M}$ & 26.8 & 4 & No & 10 & Alive \\
\hline $69 ; \mathrm{M}$ & 28.3 & 10 & No & 14 & Alive \\
\hline $71 ; \mathrm{M}$ & 26.2 & 12 & No & 6 & Alive \\
\hline $55 ; \mathrm{M}$ & 24.5 & 0 & Yes & 22 & Alive \\
\hline $60 ; M$ & 25.1 & 2 & No & 8 & Alive \\
\hline $78 ; \mathrm{M}$ & 27.8 & 1 & No & 8 & Died (treatment withdrawn) \\
\hline $56 ; \mathrm{M}$ & 26.9 & 0 & No & 18 & Alive \\
\hline $71 ; \mathrm{M}$ & 26.6 & 13 & No & 13 & Alive \\
\hline $53 ; F$ & 28.2 & 2 & No & 20 & Alive \\
\hline $53 ; \mathrm{M}$ & 26.5 & 1 & No & 14 & Alive \\
\hline $65 ; F$ & 32.1 & 16 & No & 11 & Alive \\
\hline $65 ; \mathrm{M}$ & 23.7 & 3 & Yes & 30 & Alive \\
\hline $53 ; F$ & 33.6 & 0 & No & 9 & Alive \\
\hline
\end{tabular}

collaboration between paediatric and adult intensivists and unforgettable experience. It made PICU practitioners stronger in many ways and sets in motion a stronger relationship between paediatric and adult critical care medicine in our hospital. Also, PICU occupancy remained $>80 \%$, supporting our decision not to reduce PICU capacity and not to redeploy staff.

\section{Acknowledgements}

Not applicable.

Authors' contributions

The authors drafted the manuscript and approved the final version.

\section{Funding}

Not applicable.

Availability of data and materials

Not applicable.

Ethics approval and consent to participate

Not applicable.

Consent for publication

Not applicable.

\section{Competing interests}

None to disclose for both authors.

\section{Author details}

'Department of Paediatrics, division of Paediatric Critical Care Medicine, Beatrix Children's Hospital, University Medical Center Groningen, University of Groningen, Huispost CA62, P.O. Box 30.001, 9700, RB, Groningen, The Netherlands. ${ }^{2}$ Critical Care, Anaesthesiology, Peri-operative \& Emergency Medicine (CAPE), University of Groningen, Groningen, The Netherlands. ${ }^{3}$ Department of Critical Care, University Medical Center Groningen, University of Groningen, Groningen, the Netherlands.
Received: 29 May 2020 Accepted: 8 June 2020

Published online: 16 June 2020

\section{References}

1. Gemke RJ, van der Voort E, Bos AP. The necessity for centralization of pediatric intensive care. Ned Tijdschr Geneeskd. 1997;141(48):2325-7.

2. Yager PH, Whalen KA, Cummings BM. Repurposing a Pediatric ICU for Adults. N Engl J Med. 2020;382(22):e80.

3. Epstein D, Brill JE. A history of pediatric critical care medicine. Pediatr Res. 2005;58(5):987-96

4. Kneyber MCJ, de Luca D, Calderini E, Jarreau PH, Javouhey E, Lopez-Herce J, Hammer J, Macrae D, Markhorst DG, Medina A, et al. Recommendations for mechanical ventilation of critically ill children from the Paediatric mechanical ventilation consensus conference (PEMVECC). Intensive Care Med. 2017;43(12):1764-80.

5. Remy KE, Verhoef PA, Malone JR, Ruppe MD, Kaselitz TB, Lodeserto F Hirshberg EL, Slonim A, Dezfulian C. Caring for critically ill adults with coronavirus disease 2019 in a PICU: recommendations by dual trained Intensivists. Pediatr Crit Care Med. 2020. E-pub ahead of print.

\section{Publisher's Note}

Springer Nature remains neutral with regard to jurisdictional claims in published maps and institutional affiliations. 